\title{
Central Venous Catheterization-An Anatomical Review of a Clinical Skill-Part 1: Subclavian Vein Via the Infraclavicular Approach
}

\author{
J.M. BOON,${ }^{1 \dagger}$ A.N. VAN SCHOOR,${ }^{1 *}$ P.H. ABRAHAMS, ${ }^{1,2,3}$ J.H. MEIRING, ${ }^{1}$ T. WELCH, ${ }^{4}$ AND D. \\ SHANAHAN ${ }^{5}$
}

${ }^{1}$ Department of Anatomy, University of Pretoria, South Africa

${ }^{2}$ Department of Anatomy, Girton College, Cambridge, United Kingdom

${ }^{3}$ Institute of Clinical Education, Warwick Medical School, United Kingdom

${ }^{4}$ Queen's College, Cambridge, United Kingdom

${ }^{5}$ School of Medical Education Development, University of Newcastle Upon Tyne, United Kingdom

† Deceased

The safe and successful performance of a central venous catheterization (CVC) requires a specific knowledge of anatomy in addition to a working knowledge. Misunderstanding the anatomy may result in failure or complications. This review aims to aid understanding of the anatomical framework, pitfalls, and complications of CVC of the subclavian (SCV). CVC is common practice amongst surgeons, anesthesiologists, and emergency room physicians during the preparations for major surgical procedures such as open-heart surgery, as well as, for intensive care monitoring and rapid restoration of blood volume. Associated with this technique are certain anatomical pitfalls and complications that can be successfully avoided if one possesses a thorough knowledge of the contraindications, regional anatomy, and rationale of the technique.

\section{INTRODUCTION}

A sound understanding of anatomy plays a vital role in the safe and successful performance of clinical procedures (Abrahams and Webb, 1975; McMinn et al., 1984; Beahrs et al., 1986; Crisp, 1989; Ger, 1996; American Association of Clinical Anatomists (AACA, EAC), 1999; Cottam, 1999; Boon et al., 2001). Complications that occur can often be related to a lack of understanding or misunderstanding of the anatomy essential to that specific procedure (AACA, EAC, 1999). A lack of anatomical knowledge can also prolong a procedure, which will inevitably lead to increased morbidity and mortality (Beahrs et al., 1986; Graney, 1996).

Competency to perform clinical procedures only exists when a practitioner has sufficient knowledge and manual skills required to perform the procedure safely and successfully. Competency is especially important when failure of the procedure could result in complications or cause patient discomfort (Miller, 1997). The performance of any clinical procedure needs a certain level of competency in order to be performed safely, effectively, and with few complications (O'Conner and Davidson, 1992). The Association of American Medical Colleagues (1998) state that before graduation, a student should be competent to perform certain routine technical procedures, which amongst others includes inserting an intravenous catheter.

An important part of competency is therefore a sufficient and updated knowledge base, which is necessary to perform a safe and successful procedure. Recognition of the relevant anatomy to any specific procedure remains the important basis of this knowledge. Phillips (1987) points to the importance of identifying those features of anatomical relationships that are of special interest to clinicians performing CVC. The anatomy of practical procedures often becomes a very focused and intense regional endeavor, because it deals with structures or portions thereof that are immediately and directly related to the needle, tube, or knife.

This article reviews the clinical anatomy of CVC of the subclavian vein (SCV). It starts with a step-by-step description of the different procedures and then focuses on the anatomical pitfalls and complications. 


\section{STEP-BY-STEP PROCEDURE}

1. Place the patient in a supine position, at least $15^{\circ}$ head down (Trendelenburg's position), to distend the neck veins and prevent air embolism. Only if the cervical spine has been cleared radiographically can the patient's head be turned away from the puncture site (Shimada and Sato, 1997). Place the patient's arms by his/her sides.

2. Operator should preferably stand on the same side as the puncture site (Rosen et al., 1992).

3. Sterile preparation of the skin and drape the area. Sterile gloves should be worn during the procedure.

4. Use a local anesthetic if the patient is awake. This is not necessary if the patient is under general anesthesia.

5. Introduce the desired caliber needle attached to a syringe $1 \mathrm{~cm}$ inferior and $1 \mathrm{~cm}$ lateral to the junction of the middle and medial thirds of the clavicle (see Fig. 1).

6. Direct the needle medially and slightly superiorly to stay on the inferior border of the clavicle, in the direction of the suprasternal notch where the index finger of the other hand is placed.

7. Slowly advance the needle until its tip comes in contact with the inferior border of the clavicle (Abrahams and Webb, 1975), while gently withdrawing the plunger of the syringe.

8. Gently advance the needle on the inferior border of the clavicle until the vein is entered. When free flow of blood appears, remove the syringe and occlude the needle with a finger to prevent air embolism. With newer catheter packs, the guidewire can be inserted via a separate port and the needle does not need to be removed.

9. Insert the guidewire and remove the needle. Then insert the catheter over the guidewire.

10. Remove the guidewire and connect the catheter to the intravenous line.

11. Fix the catheter in place. Subcutaneous fixation is easier to perform in the pectoral region than in the neck region (Vellani et al., 1969).

12. Attach the central venous pressure set-up to the intravenous tubing and adjust the manometer to level zero with the level of the patient's right atrium.

13. Obtain a chest X-ray to identify the position of the tip of the catheter and exclude a possible pneumo-thorax.

14. Obtain free flow intravenous fluid with gravity and flow of blood through the catheter tubing illustrated by lowering the intravenous fluid bag below the level of the patient.

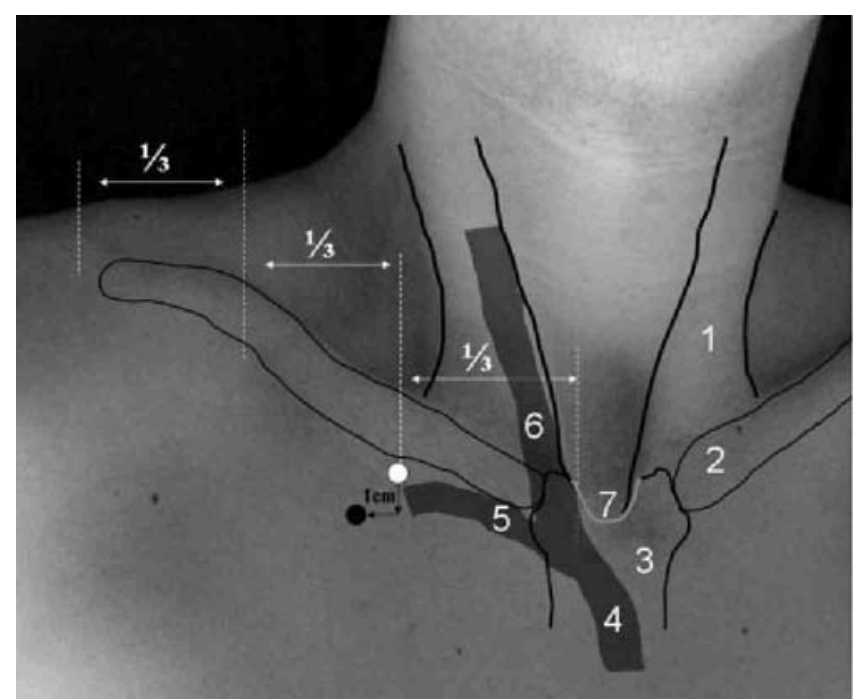

Fig. 1. Surface anatomy of the neck on the right side. Black circle indicates location for needle insertion. (1) sternocleidomastoid, (2) clavicle, (3) manubium, (4) right brachiocephalic vein, (5) right subclavian vein, (6) right internal jugular vein, (7) sternal notch. 


\section{Direction of the Needle}

The insertion site of the needle is $1 \mathrm{~cm}$ inferior and $1 \mathrm{~cm}$ lateral to the junction of the middle and medial thirds of the clavicle. The needle is advanced toward the tip of the contralateral index finger, which is placed in the suprasternal notch. The direction of the needle is now aligned with the central axis of the SCV, minimizing the risk of puncturing the subclavian artery, pleura, or apex of the lung (Moosman, 1973). By keeping the needle in a horizontal plane, the risk of arterial or pleural injury is minimized (Mathers et al., 1992).

On its course the needle goes through skin, superficial fascia, subclavius, clavipectoral fascia, and SCV.

\section{Correct Placement of Catheter Tip}

The catheter tip should be placed $3-4 \mathrm{~cm}$ above the junction of the superior vena cava and the right atrium (Blitt, 1985).

\section{Equipment Selection and Ultrasound Guidance}

The choice of equipment depends greatly on what the clinician is trying to accomplish, what equipment is available to him or what equipment he feels most comfortable using.

It should be noted that in a study conducted by Onders et al. (2006) they found that more difficulty was associated with the insertion of a larger triple-lumen catheter when compared with the smaller single lumen catheter (31\% vs. $11 \%$ respectively; $\mathrm{P}<0.009$ ). Although Lakhal et al. (2006) concluded that central venous pressure (CVP) measurement made at the distal ports of a multilumen catheter are not influenced by high flows through the proximal ports. The advantage of inserting a multilumen catheter is that it is therefore not necessary to discontinue the fluid infusion during a CVP measurement.

Ultrasound guidance is useful in helping to locate the SCV for CVC and it decreases the complications that may occur (i.e., pneumothorax and arterial puncture). However it does not decrease the technical difficulties that may occur (Hind et al., 2003). According to both Bold et al. (1998) and Lefrant et al. (1998) ultrasound guidance does not have a significant effect on improving the success rate of CVC during clinical trials and that the anatomical landmark-based technique remains reliable.

\section{PATIENT POSITION}

The patient should be positioned in the Trendelenburg position. This facilitates filling of the vein and decreases the risk of air embolism (Mathers et al., 1992).

Brederlau et al. (2004) conducted a study on 64 ventilated ICU patients (14 female, 50 male) with a median age of 52 years (range 18-85 years), needing central venous cannulation for insertion of a central venous, haemodialysis, or pulmonary artery catheter. The majority of patients presented with risk factors for a difficult cannulation and catheterization was performed using real-time ultrasound guidance with all patients positioned at $30^{\circ}$ dorsal elevation. Despite a high incidence of anomalous anatomy (39\%) there were no major complications and all attempts were successful. The authors concluded that ultrasound-guided cannulation can be performed successfully with the patient positioned at 308 dorsal elevation. Potentially deleterious position changes can thus be avoided in high-risk patients.

\section{Turning of the Head}

Turning the head should only be done if a possible neck injury has been excluded. Although anatomical studies have not confirmed the benefit of turning the head away from the site of catheter insertion (Jesseph et al., 1987), it 
may decrease the risk of contamination and patient anxiety during the procedure (Dronen and Younger, 1994).

Jesseph et al. (1987) stated that by turning the head the acuteness of the angle of the SCV and IJV is increased. They showed by means of anatomical dissection and MRI, that the traditional recommendations of positioning the patient with the shoulders retracted and the head turned away, actually distort the anatomy of the SCV, making successful cannulation of the vein more difficult. They suggest a position of lying supine with the head and shoulders in a neutral position. This is a favorable position considering the fact that many patients needing a central venous catheter in the emergency department have suspected neck injuries where manipulation of the head is totally contraindicated.

The angle of the SCV with the IJV is more or less $90^{\circ}$ (Jesseph et al., 1987), and increases when the head is turned to one side. This suggests that turning the head away from the side of the puncture may in fact promote malpositioning into the IJV. Turning the head towards the site where the procedure is performed may prevent the advancing catheter from moving into the IJV.

\section{Retraction of the Shoulders}

Retracting the shoulders by placing a sand bag or rolled towel between the scapulae of a patient, decreases the space between the clavicle and the first rib, making catheterization of the SCV more difficult (Moosman, 1973; Dronen and Younger, 1994). It is therefore better to keep the shoulders in a neutral position.

\section{ANATOMICAL PITFALLS}

\section{Subclavian Vein}

The SCV is -3-4 cm long (Moosman, 1973; Mitchell and Clark, 1979) and has a large diameter (8-9 mm) (Forutune and Feustel, 2003) and stays patent even in hypovolemia. This is due to the connective tissue around it, attaching it to surrounding structures (Mathers et al., 1992; Cahill, 1997).

In severely shocked patients, however, it may be safer to perform a long saphenous vein cutdown or attempt to access the external jugular vein. In conscious patients, or trauma patients with suspected cervical spine injury, the $\mathrm{SCV}$ route is often preferred as the technique is not influenced by head movement.

While there is a high success rate for placement of a SCV catheter, serious complications occur more commonly than with the other routes. SCV puncture should therefore be avoided in patients with abnormal clotting since it is difficult to apply pressure to the subclavian artery following accidental puncture (Hocking, 2000).

The SCV lie posterior to the medial third of the clavicle; anterior to anterior scalene, the brachial plexus and the subclavian artery; and superior to the first rib and the apical portion of the pleura.

The venous angle on both the left and right sides is formed as the IJV and SCV join to form the brachiocephalic vein. The angle of the SCV joining the IJV is $90^{\circ}$ or greater (Jesseph et al., 1987). The right lymphatic duct and the thoracic duct can be found in relation to the right and left venous angles, respectively (Mathers et al., 1992).

\section{Superior Vena Cava}

This central vein varies in length, from 3 to $10 \mathrm{~cm}$, depending on the height of the patient (Mitchell and Clark, 1979). The junction of the superior vena cava with the right atrium is one-third the distance from the suprasternal notch to the xiphoid process (Mitchell and Clark, 1979).

Carrillo-Esper et al. (2003) reported a case of a 52-year-old male presenting with a persistent left superior vena cava draining to the coronary sinus and right atrium with normal permeability of right superior vena cava. The authors emphasize awareness of congenital vascular abnormality as it can severely complicate CVC. 


\section{Subclavian Artery}

The subclavian artery runs posterior to anterior scalene, and has a superior and more posterior course than the SCV (Moosman, 1973).

\section{Phrenic Nerve}

The phrenic nerve runs on the anterior surface of anterior scalene. It lies medial to the attachment of anterior scalene to the scalene tubercle on the first rib, in contact with the postero-inferior side of the SCV where the SCV and IJV joins (Moosman, 1973). The nerve may be injured if the needle is advanced too deeply when placing a catheter in either vein. The internal thoracic artery runs in close relation to the phrenic nerve after branching from the subclavian artery (Mitchell and Clark, 1979).

Takasaki and Arai (2001) reported a case of phrenic nerve palsy after successful CVC via the SCV. According to the authors the tip of the catheter impinged upon the thin venous wall and compressed the phrenic nerve running alongside the superior vena cava.

\section{Vagus Nerve (see Fig. 2)}

The vagus nerve is located in the carotid sheath, usually posterior to the IJV (Moosman, 1973). On a lower level, the vagus nerve lies postero-medial to the venous angle (where the left SCV joins the left IJV) (Mitchell and Clark, 1979).

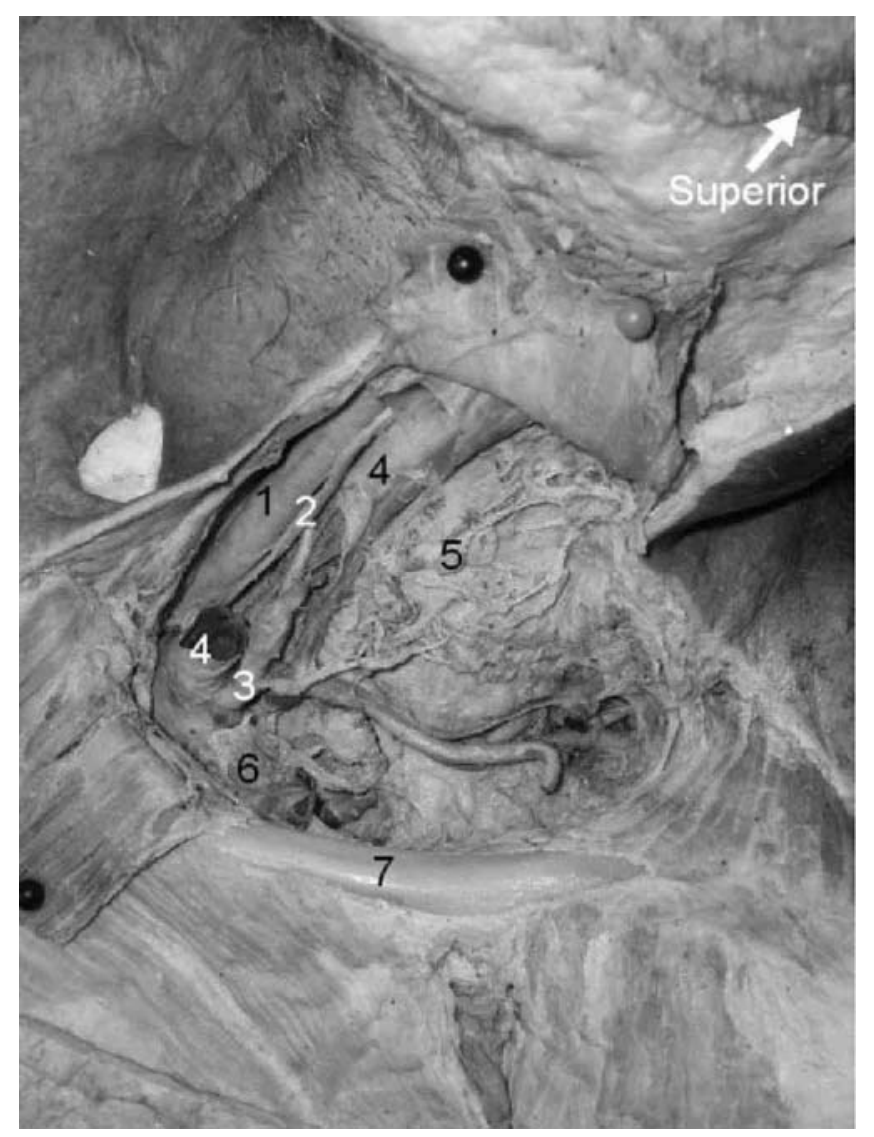

Fig. 2. Close up view of a neck dissection on the left, showing the venous angle on the left. (1) Left common carotid artery, (2) vagus nerve, (3) thoracic duct, (4) left internal jugular vein, (5) cervical lymph nodes, (6) left subclavian vein, (7) clavicle. 


\section{Thoracic Duct (see Fig. 2)}

The thoracic duct drains into the left venous angle after running across anterior scalene (Moosman, 1973). The danger of left cannulation is injury to the thoracic duct, which is a rare complication (Cobb et al., 1987; Kwon et al., 2001). However it is associated with high morbidity (Hinckley, 1969). Shimada and Sato (1997) report on several draining patterns of the terminal thoracic duct. The most common type drains into the venous angle between the SCV and IJV (38\%), followed by the type draining into the external jugular vein (28\%) and IJV (27\%), and a complex drainage pattern in $7 \%$. The thoracic duct is therefore at risk of injury when inserting a catheter into either the SCV or IJV on the left side.

\section{Right Lymphatic Duct}

This duct drains into the right venous angle (where the right SCV joins the right IJV), also running across anterior scalene (Moosman, 1973) behind the IJV (Mitchell and Clark, 1979).

\section{Apex of the Lung}

The apex of the right pleura is usually lower than the left (Dronen and Younger, 1994), making the right side the preferred side (with the thoracic duct found on the left side). If subclavian catheterization fails, first attempt the ipsilateral IJV, before considering the left side.

\section{The Cervical Pleura}

The cervical pleura is only about $5 \mathrm{~mm}$ directly posterior to the SCV, beyond the protective edge of the first rib (Smith et al., 1965). It is covered by the suprapleural membrane (Sibson's fascia) with surface markings from the junction of the medial and middle thirds of the clavicle to the sternoclavicular joint. Its highest point can be as high as $2.5 \mathrm{~cm}$ above the clavicle (Abrahams and Webb, 1975). The apical pleura is in contact with the postero-inferior surface of the SCV (Moosman, 1973; Mitchell and Clark, 1979). Therefore, if a needle is advanced through both walls of the SCV, the parietal pleura, pleural space, and lung may be penetrated with a resulting pneumothorax. A concurrent laceration of a blood vessel will result in a hemothorax or brachial plexus injury. All the roots of the brachial plexus (C5-T1) run posterior to the subclavian artery (Moosman, 1973; Mitchell and Clark, 1979).

\section{Anterior Scalene}

This muscle is attached to the scalene tubercle of the first rib, with the SCV anterior to it and the subclavian artery and brachial plexus posterior (Moosman, 1973). This muscle is $\sim 10-$ to $15-\mathrm{mm}$ thick in the adult and 5 to $8 \mathrm{~mm}$ in children (Mitchell and Clark, 1979). Thus venepuncture of the SCV has less risk of injuring the subclavian artery, which lies directly posterior to anterior scalene with the brachial plexus, which lies posterior to the subclavian artery.

\section{ANATOMICALLY RELEVANT COMPLICATIONS}

\section{Arterial Puncture}

With CVC of the SCV, arterial puncture usually involves the subclavian artery which is located posterior to the SCV (Hurwitz and Posner, 1977). Subclavian artery could be punctured if the needle is directed too far laterally and posteriorly (Mitchell and Clark, 1979).

Embolization to the carotid and basilar vessels can also occur from puncturing the subclavian artery. Hurwitz and Posner (1977) even reported two patients developing fatal cerebral infarctions after SCV catheterization associated with inadvertent arterial puncture and embolus. 
The direct result of puncturing either the subclavian artery is the formation of a hematoma (Chudhari et al., 1998). Mild to severe thrombosis may also occur, especially in long-term catheterization (Chudhari et al., 1998; lovino et al., 2001; Schummer et al., 2003), resulting in the possible compression of the surrounding structures.

Ascending aorta. One study reported the puncturing of the ascending aorta (Childs and Wilkes, 1986), within the pericardial reflection causing a fatal hemopericardium. The patient reported by Childs and Wilkes (1986) had gross abdominal distension, causing superior movement of the intrathoracic structures and therefore changes in the classical anatomical landmarks.

\section{Hemothorax}

Because of puncturing a vessel as well as the pleural membrane, a hemothorax usually occurs due to injury to a blood vessel and direct infusion of blood into the pleural cavity. A tube thoracostomy is usually required (Mitchell and Clark, 1979).

Holt et al. (1977) reported a case where an apical branch of the pulmonary artery was lacerated, with resulting hemothorax and requiring a thoracotomy.

\section{Venous Air Embolism}

Venous air embolism can occur with negative air pressure in the thorax during inspiration. If the site of insertion is vertically higher than the level of the heart an air embolism may result (Mitchell and Clark, 1979). Air moves as a bolus to the heart where it lodges at the pulmonary valve, which may break up due to ventricular contractions and enter the pulmonary circulation, cause tissue hypoxia and lowered cardiac output (Boon, 1998). Symptoms of tachypnoea, elevated jugular venous pressure, chest pain, and hypotension may be found. The mortality rate is high.

Flanagan et al. (1970) reports on the fatal outcome of venous air embolism, pointing out that a 14-gauge needle can transmit $100 \mathrm{ml}$ of air per second with a $5-\mathrm{cm}$ pressure difference across the needle. It seems that hypovolemic patients are at higher risk of developing an air embolism.

Prevention. Position the patient in the Trendelenburg position. Check catheter equipment, catheter ports, and connections. There is a higher risk with central catheters due to the connective tissue around the central veins connecting it to surrounding structures. This is especially true for the SCV. The veins therefore stay patent even in hypovolemia and have a higher risk of air embolism occurring than the peripheral veins which collapse (Cahill, 1997). The needle should be occluded in the interval between removal of the syringe and threading of the guide wire or catheter (Hegarthy, 1977).

New central venous catheters make this step unnecessary due to the fact that the guide wire is advanced through the syringe.

\section{Brachial Plexus Injury}

Injury of the brachial plexus may occur when the correct technique is not followed and the needle is not directed correctly.

The brachial plexus lies posterior to the subclavian artery posterior to anterior scalene and both cross the first rib only 2-cm lateral to the SCV (Smith et al., 1965). Therefore, brachial plexus injuries are more common with catheterization of the SCV and are usually associated with a sub-clavian artery puncture.

Injury can be caused by placement of the needle too far laterally and deeply, injuring the roots of the brachial plexus with consequent motor and sensory deficits of the shoulder, arm, or hand (Mitchell and Clark, 1979). 
Smith et al. (1965) reports on a case with brachial plexus injury where the injury consisted of motor function deficiencies to the shoulder, elbow, and hand as well as sensory loss to the lateral upper arm.

\section{Phrenic Nerve Injury}

Both Drachler et al. (1976) and Obel (1970) reported on phrenic nerve damage after SCV catheterization, with a resulting paralysis of the hemidiaphragm. This can be fatal in a patient whose respiratory function is compromised.

The phrenic nerve runs on anterior scalene, immediately behind the SCV at the puncture point (Obel, 1970). It is therefore surprising that this nerve is not injured more frequently. The nerve may also be anaesthetized by the local anesthetic injected at the site of catheter insertion. In this case, rapid recovery of diaphragmatic movement will occur.

\section{Horner's Syndrome}

Horner's syndrome has been reported to occur either due to lesions of the sympathetic chain or as a complication secondary to hydromediastinum (Milam and Sahn, 1988).

\section{Hoarseness}

Theoretically, the vagus nerve may be injured when the SCV is cannulated, by injuring the vagus nerve and therefore the recurrent laryngeal branch (Moosman, 1973).

\section{Cardiac Tamponade}

Cardiac tamponade occurs due to perforation of the superior vena cava, right atrium or right ventricle. The pericardium inserts on the base of the heart over the superior vena cava, ascending aorta, and pulmonary trunk (Sheep and Guiney, 1982). The catheter should therefore not lie too deeply, certainly not in the right atrium or ventricle (Deitel and McIntyre, 1971). Furthermore, the catheter should lie parallel to the wall of the superior vena cava. One study reports a mortality rate of $87 \%$ in patients developing cardiac tamponade (Greenall et al., 1975). Collier et al. (1984) reports that cardiac tamponade develops due to prolonged contact of the rigid catheter with the myocardial wall. Sheep and Guiney (1982) showed that cardiac tamponade is more often the result of injury to the right atrium than the right ventricle. He reports on a case of cardiac tamponade following superior vena cava perforation after using rather rigid Teflon catheters on the left hand side. It is thought that direct contact with the constantly moving vessel wall and subsequent erosion, eventually causes perforation by the catheter.

Van Haeften et al. (1988) reports on cardiac tamponade resulting from a misplaced central venous line in the pericardiophrenic vein. These veins drain to the brachiocephalic veins on both sides. Van Haeften et al. (1988) argues that this malpositioning is probably more common and deserves more attention due to a resultant potentially fatal cardiac tamponade.

Cardiac tamponade is clinically described by Beck's triad (Beck, 1937): elevated CVP decreased blood pressure and absent heart sounds. Patients may complain of chest pain (stretching of the pericardium which is innervated by the phrenic nerve), nausea (referred via the vagus nerve), abdominal pain (referred pain via the splanchnic nerves), and shortness of breath (pulmonary edema). Unexpected hypotension with venous distension in a patient with a central venous catheter should be regarded as being due to cardiac tamponade until proven otherwise (Sheep and Guiney, 1982). A high degree of suspicion should exist because the diagnosis is often delayed because of similar findings in other more common postoperative problems (Collier et al., 1984).

Cardiac tamponade is prevented by using soft polyurethrane catheters, measuring the desired length of the catheter beforehand, securing the catheter tightly to the skin and confirming the position of the catheter with a chest X-ray (Greenall et al., 1975; Sheep and Guiney, 1982; Collier et al., 1984; Boon, 1998). Catheters with beveled edges are unacceptable. 
Because of the serious nature of cardiac tamponade caused by central venous catheters, especially when the tip of the catheter is located in the right atrium, periodic radiographs are necessary to confirm correct catheter placement (Deitel and McIntyre, 1971).

Aslamy et al. (1998) argues convincingly that the absence of normative data to determine the dimensions of central venous vasculature and relationships of venous structures with radiographic landmarks complicates confirmation of the location of the catheter tip. It is proposed that the caudad margins of the clavicles correspond with the origin of the superior vena cava (Greenall et al., 1975), or approximately at the intervertebral disk between the second and third thoracic vertebrae. Greenall et al. (1975) suggests that the tip of the catheter should lie no more than $2 \mathrm{~cm}$ below a line drawn below the lower surface of each clavicle. None of these have been anatomically correlated and may well be of limited value due to the effects of parallax and radiographic technique. However, new MRI studies of the central venous anatomy have revealed better anatomical correlates to determine catheter position on a radiograph. MRI provides an opportunity to gather normative information on anatomic relationships, allowing imaging in transverse, sagittal, and coronal planes. In studying the MR anatomy of the central venous system of 101 patients, Aslamy et al. (1998) showed that the level of the right tracheobronchial angle would always be within the cephalad portion of the SVC. Their data suggest that placement of the catheter tip $<2.9 \mathrm{~cm}$ caudad to the right tracheo-bronchial angle as seen on a normal chest radiograph, avoids intracardiac placement in most patients (Aslamy et al. 1998).

Abduction and adduction of the arm, rotation of the trunk, and flexion of the neck can change the position of the tip of the catheter over a distance of several centimeters (Van Haeften et al., 1988). This may explain the development of cardiac tamponade after several days. Krog et al. (1982) examined catheter movement in a cadaver based study and found that catheters inserted correctly via antecubital veins, advance up to $7 \mathrm{~cm}$ with elevation and abduction of the arm. Displacement of catheters via the SCV was $\sim 2 \mathrm{~cm}$.

\section{Dysrhythmias}

If the tip of the catheter is too deeply placed into the right atrium or ventricle, it can irritate the wall of the heart chambers and cause dysrhythmias (Moosman, 1973).

Dysrhythmias are prevented by correctly measuring the catheter beforehand and confirming correct positioning of the tip of the catheter by a chest X-ray (Boon, 1998).

\section{Pneumothorax}

A pneumothorax is the most common complication of SCV cannulation and may be partial, total, bilateral, or under tension. It occurs with an incidence of $30 \%$ of all complications (Mitchell and Clark, 1979).

Damage to the parietal pleura is due to the surface anatomy of the cervical pleura, $2.5 \mathrm{~cm}$ above the medial third of the clavicle. A pneumothorax can usually be avoided if correct technique is used, especially the correct direction of the needle. However, repeatedly deep unsuccessful probings after failure to obtain venous blood clearly raises the chances of injuring the pleural space and producing a pneumothorax. Chest radiograph is mandatory after the procedure is performed.

Safety and the success of catheterization is increased when using imaging techniques such as venography, chest X-ray, and ultrasound (Gann and Sardi, 2003; Martin et al., 2004; Taal et al., 2004).

In a study conducted by Molgaard et al. (2004) to evaluate the value of routine chest X-ray control during central catheterisation and found no value of routine X-ray control and subsequently suggest that routine chest X-ray should be omitted. 
Maggs and Schwaber (1977) was one of the first to report on fatalities due to tension pneumothorax, bilateral pneumothorax, and combined hemopneumothorax.

Prevention. Adhere to the proper line of needle advancement. If the needle is placed too far posteriorly, the pleural cavity may be entered and the lung lacerated (Mitchell and Clark, 1979).

Abandon the procedure after two unsuccessful attempts. If the puncture and catheterization fails on one side, radiographic exclusion of a pneumothorax is advisable before attempting the other side. Clinical bedside examination may fail to pick up a slowly developing pneumothorax.

It is important that doctors who perform this procedure should be able to perform an immediate tube thoracostomy if necessary (Maggs and Schwaber, 1977).

\section{Chylothorax}

A chylothorax mostly occurs on the left side (Vellani et al., 1969; Moosman, 1973; Hegarthy, 1977). The thoracic duct drains into the left SCV where it is joined by the IJV to form the brachiocephalic vein. The smaller right lymphatic duct on the right hand side is however also at risk and puncturing can also lead to a chylothorax (Ryan, 1978).

The right lymphatic duct crosses anterior scalene to enter the superior margin of the right SCV near its junction with the IJV. Therefore placing a needle above or behind the vein or penetrating both walls could injure the right lymphatic duct.

It is however rare when compared with the left side.

Hinckley (1969) reports on a bilateral fatal chylothorax secondary to a thrombus surrounding a central venous catheter with occlusion of the thoracic duct.

Although this complication may be rare according to the literature (Cobb et al., 1987), the morbidity associated with it is high. Tachypnoea and hypotension progressing to sudden death due to a chylothorax is described. Shock develops after a latent period of lymph collection in the extrapleural space, then rupturing through the pleura. A chylo-thorax may be resolved by ligating a leaking thoracic duct, or spontaneously through development of adequate collateral circulation (Hinkley, 1969).

\section{Hydrothorax}

This complication develops when both the intrathoracic vein and pleura or pleura alone are perforated by the catheter. The intravenous fluid leaks out into the pleural space and gives the picture of a pleural effusion. Again this complication is seen in too deeply placed catheters (Boon, 1998). The hydrothorax may be bilateral because of the presence of congenital or acquired interpleural communications (Sheep and Guiney, 1982). Allsop and Askew (1975) reports a case of actual cannulation of the pleural space. This should be recognized at the time of insertion by failing to aspirate blood as the cannula is advanced and by lowering the whole infusion set below the level of the patient to observe the reflux of blood up the cannula.

\section{Hydromediastinum}

This is a rare complication, but has been documented by Adar and Mozes (1970). In their case, the movement of the catheter relative to the fixed SCV caused the tip of the catheter to perforate the brachiocephalic vein with resultant leakage into the mediastinum. The negative pressure in the mediastinum during inspiration would encourage continuous leakage. 


\section{Massive Subcutaneous Air Development}

The development of subcutaneous air may be severe enough to cause respiratory distress (Mitchell and Clark, 1979). Smith et al. (1965) reported two patients who needed a tracheostomy due to a compromised airway after SCV catheterization.

\section{Thrombosis}

Thrombosis may occur, due to initial damage caused by the catheter, which acts as a foreign body in the vein. Thrombosis is more commonly seen in long-term catheterizations. Brown et al. (1991) reports on a case of superior vena cava thrombosis in a patient with a long-term central venous line for parenteral nutrition.

Amond et al. (2002) describes a case of a pseudoaneurysm, developing on the external face of the brachiocephalic artery following the unsuccessful puncture of the right SCV, which thrombosed spontaneously.

\section{Malpositioning of Catheter Tip}

The correct position of the catheter tip is in the superior vena cava, not more than $3-4 \mathrm{~cm}$ above the junction of the superior vena cava and the right atrium (Blitt, 1985). If a saline filled catheter tip is, for example, in the superior vena cava, $5 \mathrm{~cm}$ above the reference point which is on the mid right atrial level, the recorded pressure would be 0.3 $\mathrm{cm} \mathrm{H}_{2} \mathrm{O}$ too low, which is clinically insignificant due to the consistent nature of the error in successive readings (Russell, 1974).

Sheep and Guiney (1982), and Greenall et al. (1975) argue that the tip of the catheter should lie in the proximal superior vena cava above the reflection of the pericardium and therefore above the level of the ascending aorta. Collier et al. (1984) argues for a point at least $2 \mathrm{~cm}$ above the junction of the superior vena cava and the right atrium. The pressure at this point is within $1 \mathrm{~mm} \mathrm{Hg}$ of that in the right atrium (Guyton and Jones, 1973).

Deitel and McIntyre (1971) report on catheters inserted via the subclavian route entering the IJV and passing up into the neck. Pressure applied above the clavicle or lateral rotation of the head in the direction of the operator while the catheter is advanced may inhibit its passage into the neck.

SCV catheters that are misplaced into the IJV are more common on the right (15\%) when compared with the left (2\%) (Matthews and Worthley, 1982). The reason for this is shown by the more acute angle of the right SCV with the right IJV when forming the right brachiocephalic vein when compared with the less acute angle on the left (see Fig. 3). This was confirmed on coronal magnetic resonance image (MR) studies of the two angles (Boon et al., 1999).

Complications of a malpositioned catheter may result in a hydrothorax, hemothorax, ascites (Allsop and Askew, 1975), chest wall abscess (Oakes and Wilson, 1975) (reported in a patient with long term catheterization and administration of total parenteral nutrition), chest pain (Webb et al., 1986), and embolization to the pleural space (Hegarthy, 1977).

Unusual chest pain syndromes may indicate central venous catheter malposition (Webb et al., 1986). They described this phenomenon in three incidents involving can-nulation of the left internal thoracic vein. 


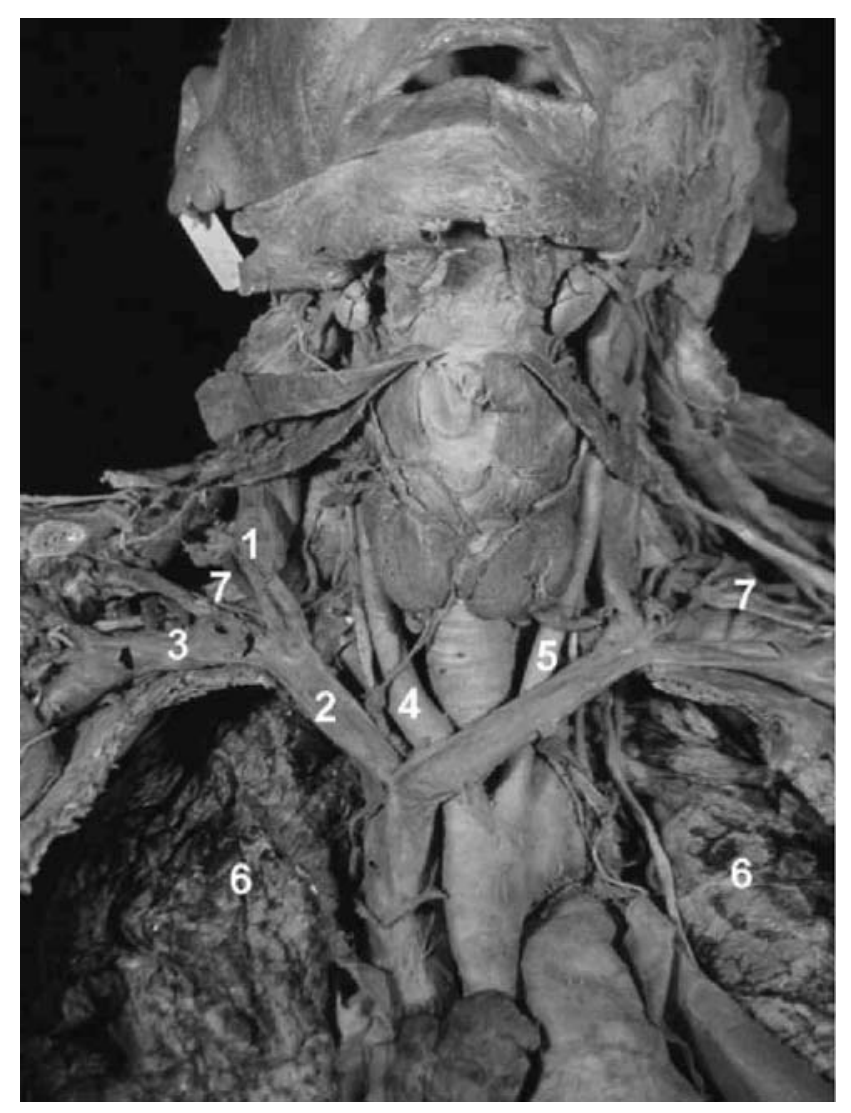

Fig. 3. Anterior view dissection of the neck indicating both the left and right subclavian and internal jugular veins. (1) Right internal jugular vein, (2) right brachiocephalic vein, (3) right subclavian vein, (4) bra-chiocephalic trunk, (5) left common carotid artery, (6) left and right lungs, (7) brachial plexus.

\section{Catheter Related Infection}

The catheter is a foreign body and may carry bacteria into the vein, which may lead to bacterial endocarditis. This is the most common complication of central catheters used long term (Brown et al., 1991).

In a study conducted by van Berge Henegouwen et al., (1982), 315 central venous catheters were placed in 194 patients in order to determine the incidence of central venous catheter-related sepsis (CRS). They concluded that the risk of catheter sepsis is not enhanced by the presence of concomitant infections located elsewhere. The low incidence and relative benign course of CRS in seriously ill patients with a surgical infection tends to widen the indication for CVC rather than to restrict it.

\section{Catheter Embolization}

This especially happens in catheter-through-needle devices. A high mortality is reported and Propp et al. (1988) points out various complications following embolization of a catheter such as arrhythmias, venous thrombosis, myocardial perforation, and pulmonary embolism. Transvenous techniques are used to retrieve the catheter, or otherwise surgery may be necessary.

Physical damage to the catheter can result in a small piece of catheter embolizing in the blood stream. Predisposing factors include the use of a catheter-through-needle device. The sharp point of the needle can easily damage the catheter, especially when the catheter is withdrawn slightly (Boon, 1998). A catheter-through-cannula device should always be used. A poorly fixed catheter may also predispose to catheter embolization.

Signs and symptoms suggesting catheter embolism include shortness of breath, palpitations, and dysrhythmias on ECG. 


\section{PREVENTION OF COMPLICATIONS}

To keep complications to a minimum, the following basic factors need to be observed (Hegarthy, 1977):

- The indications for CVC should be carefully considered.

- Thorough acquaintance of the clinical anatomy of the SCV as well as the neighboring structures. Meticulous technique should be followed.

- There is no substitute for experience. Most complications are found in the hands of inexperienced operators.

- Awareness of the complications, their frequency, and reason for occurrence is very important. The reason for the complications can in almost every instance be explained by the regional anatomy.

\section{DISCUSSION}

CVC is a common practice amongst surgeons, anesthesiologists, and emergency room physicians, during the preparations for major surgical procedures such as open-heart surgery, as well as, for intensive care monitoring and rapid restoration of blood volume.

Even in experienced hands CVC can be a risky procedure with many and severe complications. The inexperienced clinician must often select the procedure with the lowest complication rate, although possibly yielding a lower success rate. If a route is strongly indicated, the help of a more experienced clinician should be sought, if circumstance should allow (Rosen et al., 1992).

In a report of a 150 consecutive infraclavicular SCV catheterizations, Yerdel et al. (1991) found an overall complication rate of $35.5 \%$ on CVC attempts on the right and only $12.5 \%$ on the left $(P<0.01)$. In a study conducted by Conces and Holden (1984), they showed that only $63.2 \%$ of catheters inserted into the right SCV and $80.1 \%$ inserted into the left SCV where positioned properly. Onders et al. (2006) showed that the initial puncture of the SCV should be attempted on the left. Their results showed that the technical difficulty of placing a catheter into the right SCV was significantly more than into the left SCV $(24.4 \%$ vs. $10.4 \%$ respectively; $P<0.005)$.

In conclusion, the safe and successful performance of CVC demands a working and specific knowledge of anatomy and this review aids in the understanding of the anatomical framework, pitfalls, and complications of CVC.

\section{REFERENCES}

Abrahams PH, Webb P. 1975. Clinical Anatomy of Practical Procedures. London: Pitman Medical. p 32.

Adar R, Mozes M. 1970. Hydromediastinum. JAMA 214:372.

Allsop JR, Askew AR. 1975. Subclavian vein cannulation: A new complication. Br Med J 4:262.

American Association of Clinical Anatomists, Educational Affairs Committee. 1999. The clinical anatomy of several invasive procedures. Clin Anat 12:43-54.

Amond L, Haxhe JP, Frankart L, Denef R, Liessenborghs L. 2002. Spontaneous thrombosis of an iatrogenic pseudoaneurysm of the arterial brachiocephalic trunk following central venous catheterization. Ann Fr Anesth Reanim 21:530-533 [Abstract].

Aslamy Z, Dewald CL, Heffner JE. 1998. MRI of central venous anatomy. Implications for central venous catheter insertion. Chest 114:820-826.

Association of American Medical Colleagues. 1998. Learning Objectives for Medical Student Education. Guidelines for Medical Schools. Washington: AAMC. p 5-6. 
Beahrs OH, Chase RA, Ger R. 1986. Gross anatomy in medical education. Am Surg 52:227-232.

Beck GS. 1937. Acute and chronic compression of the heart. Am Heart J 14:515.

Blitt CD. (ed.) 1985. Monitoring in Anaesthesia and Critical Care Medicine. Central Venous Pressure Monitoring. New York, NY: Churchill Livingstone. p 121-165.

Bold RJ, Winchester DJ, Madary AR, Gregurich MA, Mansfield PF. 1998. Prospective, randomized trial of Doppler-assisted subclavian vein catheterization. Arch Surg 133:1089-1093.

Boon JM. 1998. Monitering van resussitasie in 'n perifere omgewing deur perifere sentraal veneuse lyne. Dissertation MMed (Family Medicine) University of Pretoria.

Boon JM, Richards PA, Baumbach J, Scholtz L. 1999. Left or right access for successful central venous catheterization-the anatomical answer: A preliminary study. Clin Anat 12:199-212.

Boon JM, Meiring JH, Richards PA, Jacobs CJ. 2001. Evaluation of clinical relevance of problem-oriented teaching in undergraduate anatomy at the University of Pretoria. Surg Radiol Anat 23:1-4.

Brederlau J, Greim C, Schwemmer U, Haunschmid B, Markus C, Roewer N. 2004. Ultrasound-guided cannulation of the internal jugular vein in critically ill patients positioned in 30 degrees dorsal elevation. Eur J Anaesthesiol 21:684-687.

Brown RA, Millar AJW, Cywes S. 1991. Central venous catheters. Technique and experience at Red Cross War Memorial Children's Hospital, Cape Town, 1987-1990. S Afr Med J 80:11-13.

Cahill DR. 1997. Lachman's Case Studies in Anatomy. 4th Ed. New York: Oxford University Press. p 94.

Carrillo-Esper R, Contreras-Dominguez V, Salmeron-Najera P, Carvajal-Ramos R, Hernandez-Aguilar C, Juarez-Uribe A. 2003. Persistent left superior vena cava: Infrequent localization of central venous catheter. Cir Cir 71:319-323 [Abstract].

Childs D, Wilkes RG. 1986. Puncture of the ascending aorta-A complication of subclavian venous cannulation. Anaesthesia 41:331.

Chudhari LS, Karmakar US, Dixit RT, Sonia K. 1998. Comparison of two different approaches for IJV cannulation in surgical patients. J Postgrad Med 44:57-62.

Cobb LM, Vinocur CD, Wagner CW, Weintraub WH. 1987. The central venous anatomy in infants. Surg Gynecol Obstet $165: 230-234$.

Collier PE, Ryan JJ, Diamond DL. 1984. Cardiac tamponade from central venous catheter: A report of a case and review of the English literature. Angiology 35:595.

Conces DJ, Holden RW. 1984. Aberrant locations and complications in initial placement of subclavian vein catheters. Arch Surg 119:293-295.

Cottam WW. 1999. Adequacy of medical school gross anatomy education as perceived by certain postgraduate residency programs and anatomy course directors. Clin Anat 12:55-65.

Crisp $\mathrm{AH}$. 1989. The relevance of anatomy and morbid anatomy for medical practice and hence postgraduate and continuing medical education of doctors. Postgrad Med J 65:221-223.

Deitel M, McIntyre JA. 1971. Radiographic confirmation of the site of central venous pressure catheters. Can J Surg 14:42-52.

Drachler D, Kopeke G, Weg J. 1976. Phrenic nerve injury from subclavian vein catheterization: Diagnosis by electromyography. JAMA 236:2880.

Dronen SC, Younger JG. 1994. Central catheterization and central venous pressure monitoring. In: Pfenninger JL, Grant CF. (eds.) Procedures for Primary Care Physicians. St. Louis: Mosby. p 270.

Flanagan J, Gradisar I, Gross R. 1970. Air embolus-A lethal complication of subclavian venepuncture. N Engl J Med $281: 372$.

Forutune JB, Feustel P. 2003. Effects of patient position on size and location of the subclavian vein for percutaneous puncture. Arch Surg 138:996-1000.

Gann M Jr, Sardi A. 2003. Improved results using ultrasound guidance for central venous access. Am Surg 69:1104-1107.

Ger R. 1996. Basic surgical training. 4: American and British scenes compared. Clin Anat 9:173-174.

Graney DO. 1996. Letter to the editor. Clin Anat 9:61. 
Greenall MJ, Blewitt RW, McMahon MJ. 1975. Cardiac tamponade and central venous catheters. Br Med J 2:595.

Guyton AC, Jones CE. 1973. Central venous pressure: Physiological significance and clinical implications. Am Heart J 86:431437.

Hegarthy MM. 1977. The hazards of subclavian vein catheterization: Practical considerations and an unusual case report. S Afr Med J 52:250.

Hinckley ME. 1969. Thoracic-duct thrombosis with fatal chylothorax caused by a long venous catheter. N Engl J Med 280:9596.

Hind D, Calvert N, McWilliams RG, Davidson A, Paisley S, Beverley C, Thomas S. 2003. Ultrasonic locating devices for central venous cannulation: Meta-analysis. Br Med J 327:361-364.

Hocking G. 2000. Central venous access and monitering. Update in Anaesthesia-Practical Procedures Issue 12 Article 13. URL: http://www.nda.ox.ac.uk/wfsa/html/u12/u1213 01.htm [Accessed 18 July 2006].

Holt S, Kirkham N, Myerscough E. 1977. Hemothorax after subclavian vein cannulation. Thorax 32:101-103.

Hurwitz BJ, Posner JB. 1977. Cerebral infarction complicating subclavian vein catheterization. Ann Neurol 1:253.

Iovino F, Pittiruti M, Buononato M, Lo Schiavo F. 2001. Central venous catheterization: Complications of different placements. Ann Chir 126:1001-1006 [Abstract].

Jesseph JM, Dewey JC, Augustyn GT. 1987. Patient positioning for subclavian vein catheterization. Arch Surg 122:1207-1209.

Krog M, Berggren L, Brodin M, Wickbom G. 1982. Pericardial tamponade caused by central catheters. World J Surg 6:138143.

Kwon SS, Falk A, Mitty HA. 2001. Thoracic duct injury associated with left internal jugular vein catheterization: Anatomic considerations. J Vasc Interv Radiol 13:337-339.

Lakhal K, Ferrandière M, Lagarrigue F, Mercier C, Fusciardi J, Laffon M. 2006. Influence of infusion flow rates on central venous pressure measurements through multi-lumen central venous catheters in intensive care. Intensive Care Med 32:460-463.

Lefrant JY, Cuvillon P, Benezet JF, Dauzat M, Peray P, Saissi G, de La Coussaye JE, Eledjam JJ. 1998. Pulsed Doppler ultrasonography guidance for catheterization of the subclavian vein: A randomized study. Anesthesiology 88:1195-1201.

Maggs PR, Schwaber JR. 1977. Fatal bilateral pneumothoraces complicating subclavian vein catheterization. Chest 71:552.

Martin MJ, Husain FA, Piesman M, Mullenix PS, Steele SR, Andersen CA, Giacoppe GN. 2004. Is routine ultrasound guidance for central line placement beneficial? A prospective analysis. Curr Surg 61:71-74.

Mathers LH, Smith DW, Frankel L. 1992. Anatomic considerations in placement of central venous catheters. Clin Anat 5:89106.

Matthews NT, Worthley LIG. 1982. Immediate problems associated with infraclavicular subclavian catheterization: A comparison between left and right sides. Anesth Int Care 10:113.

McMinn RMH, Hutchings RT, Logan BM. 1984. A Colour Atlas of Applied Anatomy. London: Wolfe Medical Publications.

Milam MG, Sahn SA. 1988. Horner's syndrome secondary to hydromediastinum. A complication of extravascular migration of a central venous catheter. Chest 94:1093-1094.

Miller M. 1997. Education, training, and proficiency of procedural skills. Prim Care 24:231-240.

Mitchell SE, Clark RA. 1979. Complications of central venous catheterization. AJR Am J Roentgenol 133:467-476.

Molgaard O, Nielsen MS, Handberg BB, Jensen JM, Kjaergaard J, Juul N. 2004. Routine X-ray control of upper central venous lines: Is it necessary? Acta Anaesthesiol Scand 48:685-689.

Moosman DA. 1973. The anatomy of infraclavicular subclavian vein catheterization and its complications. Surg Gynecol Obstet 136:71.

Oakes DD, Wilson RE. 1975. Malposition of subclavian lines. JAMA 233:532.

Obel IW. 1970. Transient phrenic nerve paralysis following subclavian venepuncture. Anesthesiology 33:369. 


\section{openUP}

Onders RP, Shenk RR, Stellato TA. 2006. Long-term central venous catheters: Size and location do matter. Am J Surg 191:396- 399 .

Phillips LG. 1987. Anatomy: How much or how little and taught by whom? Am Surg 53:540-542.

Propp DA, Cline D, Hennenfent BR. 1988. Catheter embolism. J Emerg Med 6:17.

Rosen M, Latto P, Ng S. (eds.) 1992. Handbook of Percutaneous Central Venous Catheterization. 2nd Ed. London: Saunders.

Russell WJ. 1974. Central Venous Pressure. Its Clinical Use and Role in Cardiovascular Dynamics. London: Butterworths. p 43.

Ryan DW. 1978. Lymph leakage following catheterization of the right subclavian vein. Anesth Analg 57:123.

Schummer W, Schummer C, Hoffmann E. 2003. Chylothorax after central venous catheterization. Considerations to anatomy, differential diagnosis and therapy. Anaesthesist 52:919-924. [Abstract].

Sheep RE, Guiney WB. 1982. Fatal cardiac tamponade: Occurrence after left internal jugular vein catheterization. JAMA 248:1632.

Shimada K, Sato I. 1997. Morphological and histological analysis of the thoracic duct at the jugulo-subclavian junction in Japanese cadavers. Clin Anat 10:163-172.

Smith BE, Modell JH, Gaub ML, Moya F. 1965. Complications of subclavian vein catheterization. Arch Surg 90:228-229.

Taal MW, Chesterton LJ, McIntyre CW. 2004. Venography at insertion of tunnelled internal jugular vein dialysis catheters reveals significant occult stenosis. Nephrol Dial Transplant 19:1542-1545.

Takasaki Y, Arai T. 2001. Transient right phrenic nerve palsy associated with central venous catheterization. Br J Anaesth 87:510- 511.

Van Berge Henegouwen DP, Leguit P Jr, Boissevain AC, Hovius SE, Amer F, Brummelkamp WH, Zanen HC. 1982. The risk of central venous catheter-related sepsis in patients with surgical infections. Neth J Surg 34:201-205.

Van Haeften TW, Van Pampus ECM, Boot H, Strack van Schijndel RJ, Thijs LG. 1988. Cardiac tamponade from misplaced central venous line in pericardiophrenic vein. Arch Intern Med 148:1649.

Vellani CW, Tildesley G, Davies LG. 1969. Endocardial pacing: A percutaneous method using the subclavian vein. Br Heart J 31:106.

Webb JG, Simmonds SD, Chan-Yan C. 1986. Central venous catheter malposition presenting as chest pain. Chest 89:309.

Yerdel MA, Karayalcin K, Aras N, Bozatli L, Yildrim E, Anadole E. 1991. Mechanical complications of subclavian vein catheterization-A prospective study. Int Surg 76:18-22. 